\title{
Challenges in Medical Education
}

\section{Training Physicians to Work Collaboratively}

\author{
Mary Ramsbottom-Lucier, MDCM, MPH, Janet Pregler, MD, Arthur G. Gomez, MD
}

$\mathbf{I}_{\mathrm{r}=\mathrm{n}^{\mathrm{n}}}^{\mathrm{n}}$ an ideal setting, generalists and specialists collaborate to provide quality care to individual patients and patient populations covered by a variety of health care plans. To accomplish this, generalists and specialists must each understand the other's domain and area of expertise. In many managed care settings, generalists must expand competencies. In turn, specialists must understand the extent of care generalists can provide. ${ }^{1}$ Skills required for both groups include incorporating population-based, costeffective, and evidence-based medicine into daily practice. ${ }^{2-4}$

Specialists and generalists must be able to communicate in an efficient and timely manner to optimize consultations between physicians. The referring physician should specify the question and provide essential information to the consultant, while the consulting physician should address the question and participate in monitoring the patient's care to ensure appropriate treatment. ${ }^{2,3,5-9}$

Generalists and specialists collaborate in the care of patients with the most complex problems. Ideally, generalists and specialists would develop consistent referral paths, and be located near one another to permit personal professional relationships. Respect, trust, and the ability to work as part of a team are the foundations for this relationship..$^{2,3,9}$

\section{CURRICULAR GOALS AND OBJECTIVES}

Learning to establish this ideal relationship should be a training goal for medical students, residents, and practicing physicians. Generalists and specialists practicing in a managed care environment advocate for their patients and must be able to communicate effectively with physicians and nonphysicians involved in health care decisions. Managed care organizations rely on outcome measures and guidelines to assess and manage care. Physicians must be able to evaluate whether proposed outcome measures and guidelines are appropriate, and articulate their concerns if they are not. Managed care organizations balance market forces with the need to deliver quality medical care. In this paradigm, physicians must have the knowledge and skills to ensure that "marketing" enhances

Received from the Department of Internal Medicine, University of Kentucky College of Medicine, Lexington, Ky. (MRL); the Department of Internal Medicine, University of California, Los Angeles, Calif. (JP, AGG); and the VAMC, Sepulveda, Calif. (AGG).

Address correspondence and reprint requests to Dr. Ramsbottom-Lucier: General Internal Medicine, University of Kentucky, K507 Kentucky Clinic, Lexington, KY 40536-0284. outcomes, rather than causing patient care to suffer. Physicians may participate at an administrative level, but excellent patient care will not be maintained without continued advocacy from all practicing physicians.

There is a general perception that these issues are not addressed in undergraduate, graduate, or continuing medical education curricula. To be effective, these topics should be introduced to medical students and reinforced during graduate medical training and continuing medical education. Certain skills, particularly computer skills, might be considered as prerequisites for entry into medical school. For current residents and practicing physicians, ongoing continuing medical education programs should be developed. Didactic formats can be used to present the foundations of each area; experiential learning is important to ensure that physicians can apply these topics to their practice.

\section{Clinical Practice}

Irrespective of the practice setting, generalists need a solid foundation of clinical skills to provide primary care and to refer patients appropriately. Generalists need to know which specialist has the appropriate skills to assist in the patient's care. In turn, specialists need to have an understanding of the scope of practice of generalists. Generalists and specialists must show respect for all members of the health care team and appreciate the contribution of each. ${ }^{2,3,6-9}$

\section{Basic Clinical Epidemiology and Population-Based Medicine}

In a managed care environment, physicians will care for defined groups of patients. To effectively use the health care resources, generalists and specialists need to be aware of the prevalence of illnesses and the major causes of morbidity and mortality for their patients. ${ }^{3,4,6,7,9}$

\section{Medical Informatics}

The management of information is important for the practice of medicine. Computerized patient databases and electronic medical information have become indispensable in the practice of medicine. They allow for the analysis of practice patterns and quality improvement. ${ }^{6,8,9}$

\section{Lifelong Learning Skills}

Physicians need to judge new evidence as it is published and incorporate it into practice. In managed care, 
generalists and specialists will need to participate in the creation and dissemination of practice guidelines. Further, a physician who must deviate from the protocol for specific patients will need to present an informed argument to the health care plan administrators. ${ }^{3,5,8,9}$

\section{Appropriate Timing of Referrals Between Physician Colleagues}

The economic pressures of managed care highlight the need to refer patients when specialized intervention can provide the most benefit. Good communication skills facilitate the referral process..$^{2,3,5-9}$

\section{Quality Assurance Methodology}

Specific quality assurance methodologies, including delivery of preventive care, access to care, utilization rates for procedures, hospital admissions, and length of stay, can be used to monitor the care provided. Generalists and specialists need to understand how the data are collected, analyzed, and applied to improve care. , $^{6-10}$

\section{Utilization Review and Preauthorization}

Many insurers require preauthorization processes to monitor the use of technology and specialty referrals. All physicians need to understand the process and be able to articulate their rationale for medical decisions. ${ }^{8-10}$

\section{IMPLEMENTING CURRICULUM}

To illustrate the implementation of these curricular goals and objectives, we discuss examples from three institutions: an academic private practice in a market with high penetration of managed care, a Veteran Affairs Medical Center (VAMC) practice surrounded by a market with high penetration of managed care, and an academic practice in a market with low penetration of managed care. None of these programs encompasses all of the skills above; however, each highlights certain accomplishments and identifies barriers to implementation at the respective institution. Even as this article is written, these programs are evolving and changing in response to internal and external pressures. ${ }^{11}$

\section{High Penetration of Managed Care, Private Practice Model}

Training in managed care issues at the University of California at Los Angeles (UCLA) Center for Health Sciences developed as part of an institutional response to the high penetration of managed care in the surrounding marketplace. In 1984, the Primary Care Group of UCLA signed its first contract with a health maintenance organization. More than $60 \%$ of patient visits to the general internal medicine department are covered by managed care organizations. Because of this history of working in a managed care setting, this program has incorporated the majority of the concepts outlined above.

Collaborative relationships between generalists and specialists are supported by major changes in the faculty medical practice, including increasing utilization review, expansion into community practices, and addition of general internal medicine clinician-educators. Collaboration between generalists and specialists is required for consultations and procedures. The community-based physicians are role models for trainees, as they practice collaboratively with their specialist colleagues.

At UCLA, residents and faculty form an integrated practice. Many managed care organizations require that designated primary care physicians be board eligible or certified, and available to patients for a certain number of hours each week in the outpatient setting. This requirement is a potential barrier to resident participation as primary care physicians. To address this issue during contract negotiations, generalists argued that there are special benefits to an academic medical center for members of health plans. They convinced plans to allow patients to designate the primary care group, rather than an individual physician, as their primary care provider for purposes of access and billing.

The UCLA faculty adopted peer outpatient utilization review. Nonemergent requests for consultation, high-cost radiologic tests, durable medical equipment, and procedures are subjected to review. Routine requests, as defined by the committee, are automatically approved. Generalists participate on a regular basis; specialists are asked for comment or clarification when issues pertinent to their specialty are discussed. Over the past several years, interns and residents have attended these committee meetings as part of their outpatient experience.

To promote communication between specialists and generalists, specialists cannot initiate testing or follow-up without first communicating with the primary care physician. Further, in order for referrals to be approved, the written referral must contain appropriate information for the specialist, including the specific question to address and results from any prior evaluation. As primary care physicians, residents coordinate the care of their patients, including initiating referrals and communicating with specialists. This process encourages critical self-evaluation of knowledge and skills, and provides continual feedback about the appropriate and effective use of consultants.

Lifelong learning skills are presented as part of a didactic curriculum in evidenced-based medicine. Topics include critical reading of the medical literature, evaluation of guidelines, and effective use of screening tests and consultations. Medical informatics, including basic computer skills such as the use of the Internet and computerized medical record systems, are emphasized. 
As part of an outpatient firm system, residents meet weekly with a faculty member in an outpatient morning report. In addition to providing a setting for clinical teaching, this meeting models the generalist as problem solver, and emphasizes practical aspects of how generalists maintain and improve their skills and knowledge. Effective collaboration with consultants, for the purpose of individual patient care, as well as for lifelong learning, is a continual topic in these sessions.

Other aspects of the curriculum that promote collaborative relationships with specialists are currently under development. Residents and generalists and specialist faculty work together to review and adapt published guidelines for use in the UCLA practice, including guidelines for the treatment of acute low-back pain, evaluation of kidney stones, and use of Holter monitors and event recorders for evaluation of palpitations. In addition, generalists and specialists are adapting the Federated Council of Internal Medicine (FCIM) curriculum for the residency training program.

Perceived Barriers to Implementation. At UCLA, the financial constraint imposed by the high penetration of managed care has both enhanced and impeded collaborative relationships between generalists and specialists. Certain market forces provide strong financial incentives for specialists to market themselves to patients, and to provide direct care rather than assuming a consultative and collaborative role. As is true in academic medicine, not all specialist faculty support the concept of generalism and reject the collaboration between generalists and specialists to define the knowledge base needed for generalists. At times, both generalists and specialists exhibit defensive attitudes about their "turf," from intellectual and financial aspects. Finally, hierarchical attitudes, present in internal medicine training since its beginnings, still exist. For many faculty and residents, the opinion of an expert carries more weight than the outcome of carefully performed research. The practice of evidence-based medicine, although generally lauded, is not yet completely accepted as the standard on which patient care should be based.

In the past year, UCLA began evaluating subcapitation as a way of eliminating some of the financial incentives that caused specialists to provide direct care rather than assume a consultative, collaborative role. Under this model, specialty areas receive a set capitation payment for all specialty care of a given group of patients, which is a change from the modified fee-for-service strategy under which specialists were previously reimbursed for care of capitated patients. This has already resulted in initiatives from some specialty areas to increase generalist knowledge and skills in the care of certain common problems. Conversely, under this model, once the generalist refers the patient to the specialist, communication is not required before the specialist requests further evaluation or treatment of a patient. There is a concern that collabora- tion and comanagement for individual patients may suffer under this new paradigm.

\section{High Penetration of Managed Care, Veteran Affairs Medical Center Practice}

At the UCLA-San Fernando Valley program (Sepulveda VAMC and Olive View County Hospital), training in managed care developed as a response to the market pressures graduates faced when leaving the program. This residency program conducts outpatient training predominantly in the Sepulveda VAMC clinics. Despite the high penetration of managed care in California, the VAMC training sites are remarkably sheltered from managed care practices that control resource utilization. Although some may consider the VAMC one of the largest managed care organizations in the country, the measures used to manage resources are not explicit and are certainly not apparent to trainees. This program primarily addresses the referral process and utilization review.

Planning for this curriculum was driven by the need to address the recommendations from the Council on Graduate Medicine Education (COGME) for training in managed care. In addition, subspecialty clinics experienced excessively long waiting times to available appointments, with impressions that many patients routinely followed in these clinics could be cared for by primary care physicians. To address these concerns, a working group was established and charged with several goals: create an ambulatory utilization review process for reviewing referrals, decrease inappropriate referrals by identifying problems that generalists should treat, improve referral documentation, and educate residents about managed care.

Similar to the UCLA process, the VAMC utilization review process uses experiential learning to teach residents coordination of all aspects of health care. As part of providing ongoing primary care to patients, residents must coordinate referrals for subspecialty care and the use of technology. When utilization review meetings were introduced initially, residents and faculty reviewed consultations for all specialties. Over time, behavioral, social service, and patient education consultations were consistently accepted and subsequently excluded from routine committee review. However, the review committee found some medical and surgical subspecialty consultations to be unnecessary. Areas in which faculty needed training in procedures and management issues were identified, and the training was undertaken. Specialists began to receive more appropriate referrals, and the medical center supported expansion of managed care efforts.

Residents serve on the review committee, where they vote to accept, reject, or amend referral requests along with faculty participants. Evidence-based practice and the use of guidelines became the most logical way to decide cases. Some published guidelines were modified for the specific patient population and resources. For example, given the aging population and finite resources at the 
VAMC, screening for colorectal cancer with flexible sigmoidoscopy is routinely approved for patients between ages 50 and 70 . However, for patients over age 70, the individual clinical situation is considered before approval is given. When no evidence-based guidelines exist for a diagnosis, residents are assigned to consult the literature and develop local recommendations. Residents have the opportunity to develop communication and advocacy skills when they present cases and defend their rationale for management decisions that are controversial.

Specific programmatic elements were necessary to begin the utilization review process at the VAMC. Administrators and residency directors provided physician leadership. The educational process included generalists and specialists working collaboratively. Urgent referral mechanisms were developed a priori. And finally, opportunities for communication between the physician requesting the referral and the utilization review committee were established and maintained. These components required support staff to handle referral forms and ensure appropriate handling of accepted and rejected requests. When the requesting physician was not present at the utilization review meeting, communication was established through electronic mail, notes on paper, and pagers. Further, primary care physicians are required to notify patients of the decision.

Perceived Barriers to Implementation. In implementing this utilization review program, major barriers were identified. The VAMC faculty practice in a sheltered environment at a public, academic hospital where managed care had not been explicit. Naturally, there was resistance to an unknown process that scrutinized the delivery of patient care. The curriculum for internal medicine residency training was already very full; this new managed care curriculum had to compete with other training agendas. The utilization review meetings had to be educational and stimulating to maintain the residents' interest. In addition, the VAMC system itself is not conducive to rapid change and is constrained by limited clerical and secretarial resources.

However, our experience with exposing internal medicine residents to utilization review at a VAMC illustrated benefits that counter the drawbacks. Residents who participated in the utilization review process decreased their utilization and improved their referral documentation. Their attitude became more positive; they were more familiar with the need to explicitly specify the referral question and less resentful of the review process. However, active participation in utilization review needed to be continuous so that the changes in behavior did not deteriorate. After 4 weeks without participating in utilization review, residents reverted to their earlier referral patterns. Fortunately, long-term attitudinal benefits are apparent. Already, several graduates have thanked us for exposing them to managed care practices they are now encountering on a daily basis. ${ }^{12,13}$

\section{Low Penetration of Managed Care, Academic Practice}

At the University of Kentucky, curriculum for managed care is being developed without the benefit of practice sites and organizational structures with expertise in treating patients under managed care, although the Commonwealth of Kentucky introduced a managed care program for Medicaid recipients in 1998. Nonetheless, several of the core concepts are introduced in both the undergraduate and postgraduate curricula. Collaborative relationships between generalists and specialists are more difficult to model in the current environment.

With the assistance of a grant from the Robert Woods Johnson Foundation, the undergraduate curriculum was revised in the early 1990s. This revised curriculum includes a focus on lifelong learning skills, early clinical exposure, and during the preclinical years, training in basic epidemiology and clinical decision making, including critical appraisal skills as well as electronic communication, and literature searching. Critical appraisal and computer skills are reinforced during the clinical years by having the students participate in a Web-based discussion list, complete literature searches relevant to patient care, and critically appraise the articles retrieved. In addition, all fourth-year students participate in a 2-week dean's colloquium, which consists of case-based discussions led by generalist and specialist faculty. One case involves providing care to a patient in a managed care setting. In order to implement this curriculum, ongoing faculty development has been necessary.

At the resident level, the ambulatory practice sites for general internal medicine at both the University of Kentucky Clinic and the Lexington VAMC have been organized into resident-attending physician teams, which provide continuity of care for patients and access to a team member throughout the week. During ambulatory block rotations, residents participate in didactic teaching sessions and rotate through a variety of specialty clinics, such as otolaryngology, ophthalmology, gynecology, sports medicine, and breast clinic. Didactic topics include chart documentation, literature searching, critical appraisal, electronic communication, and word processing and database computer skills.

At morning report, inpatient and outpatient cases are presented. Both generalist and specialist faculty participate in the discussion, including the appropriate utilization of resources and referrals. All residents rotate through the general internal medicine consult service, providing inpatient and outpatient consultations to colleagues in other specialties. During this rotation and the rotations on various medicine subspecialty services, residents learn effective consultation techniques through readings, didactic conferences, and role modeling by their faculty.

Each fall, the Department of Internal Medicine sponsors a retreat for residents, during which time seminars and 
case discussions are held. In recent years, sessions included managed care, a discussion of different organizations of health care providers, and cost-effectiveness, a case-based discussion between generalists and specialists for the management of a patient with secondary hypertension. Noon conferences held throughout the year complement these seminars.

As the Medicaid program has implemented its first phases of managed care, a committee of generalists and specialists has organized seminars to introduce the role of the gatekeeper to all faculty and residents. Providerspecific reports, which include patient waiting times and satisfaction, are distributed to generalist and specialist faculty and will soon be available for individual residents. In the near future, cross-disciplinary seminars on managed care will be presented to residents.

Perceived Barriers to Implementation. There are many barriers to implementing these curricular elements in a location where faculty and residents do not face the realities of managed care in their clinical practice. Faculty development, from training in the basic vocabulary of managed care to the new role of generalists as gatekeepers, is a necessary first step, yet resisted by some. Faculty must learn the steps involved in quality assurance and utilization review before they can provide experiential learning opportunities for medical students and residents.

\section{CONCLUSIONS}

The changes in the delivery of health care require that a curriculum for medical students and residents include components that will provide training to work in collaborative relationships. The curriculum should include adequate training in clinical practice, clinical epidemiology and population-based medicine, medical informatics, skills for lifelong learning, quality assurance, utilization review, and an understanding of the appropriate timing of referrals between generalists and specialists. Training modalities should include didactic format to provide a foundation and experiential learning to allow the individual to integrate the knowledge, skills, and attitudes required to practice as a collaborative colleague with other physicians and members of the health care delivery team.

These three programs provide examples of how this content is introduced into a curriculum. All three programs are in the process of evolution and evaluation. Successful programs build on the current practice environment, with an eye to what the future might be like, and garner support from all levels, from the leaders among the faculty to the trainees and support staff. Ongoing improvements are an integral part of implementation at each institution, as barriers are recognized and addressed, as problems are acknowledged and solutions are proposed, and as the practice environment changes in response to market pressure.
These three examples are limited in their view - each is institutionally based and, as such, may not generalize to other settings. The keystone for the models at institutions in markets with high penetration of managed care is experiential learning about utilization review. ${ }^{11}$ Although this piece is undoubtedly important, it does not encompass all the facets of practice in a managed care setting. The keystone for the institution in a market with low penetration of managed care is to begin with faculty development and didactic sessions for trainees, which include casebased discussions as a proxy for the experiential learning available in other clinical settings. Evaluation of these different programs is under way, but not yet completed.

The examples illustrate one major point: it is easier to teach these topics didactically than it is to provide an adequate environment for experiential learning. The challenge to all training programs is to develop and evaluate programs that address all these curricular areas and provide the trainee with both didactic and experiential learning opportunities.

\section{REFERENCES}

1. Nielson EG. When does a generalist need a specialist? J Gen Intern Med. 1996;11:247-8.

2. Reynolds PP, Giardino AG, Onady GM, Seigler EL. Collaboration in the preparation of the generalist physician. J Gen Intern Med. 1994;9(suppl):S55-63.

3. Council on Graduate Medical Education. Managed Care: Implications for the Physicians Workforce and Medical Education. Sixth Report of the Council. Washington, DC: Department of Health and Human Services; 1995.

4. Greenlick MR. Educating physicians for population-based clinical practice. JAMA. 1992;267:1645-8.

5. Rosenthal TC, Riemenschneider TA, Feather J. Preserving the patient referral process in the managed care environment. Am J Med. 1996; 100:338-43.

6. Rivo ML, Mays HL, Katkoff J, Kindig DA. Managed health care implications for the physician workforce and medical education. JAMA. 1995;274:712-5.

7. Wartman SA. Managed care and its effect on residency training in internal medicine. Arch Intern Med. 1994;154:2539-44.

8. Finocchio LJ, Bailiff PJ, Grant RW, O’Neil EH. Professional competencies in the changing health care systems: physicians' views on the importance and adequacies of formal training in medical school. Acad Med. 1995;70:1023-8.

9. Group Health Association of America. Primary Care Physicians: Recommendations to Reform Medical Education: Competencies Needed to Practice in HMOs. Washington, DC: Group Health Association of America; 1993.

10. Kerr EA, Mittman BS, Hays RD, Siu AL, Leake B, Brook RH. Managed care and capitation in California: how do physicians at financial risk control their own utilization. Ann Intern Med. 1995; 123:500-4.

11. Gomez AG, Grimm CT, Yee EFT, Shootsky SA. Preparing residents for managed care practice using an experienced-based curriculum. Acad Med. 1977;72(11):959-65

12. Grimm CT, Wali S, Gomez AG. Utilization review decreased referrals to subspecialists. J Gen Intern Med. 1996;11(1 suppl):S100.

13. Wali G, Grimm CT, Gomez AG. What providers think about utilization review - the haves and the have-nots. J Gen Intern Med. 1996;11(1suppl):S110. 